\title{
AS TECNOLOGIAS DIGITAIS NO ENSINO E NA APRENDIZAGEM DO PORTUGUÊS
}

\author{
Marcos José Fernandes de Freitas ${ }^{1}$ \\ ${ }^{1}$ Universidade de Fortaleza (UNIFOR) e Faculdade Integrada da Grande Fortaleza (FGF) \\ $<$ marcos_freitas@ymail.com>
}

DOI: 10.21439/conexoes.v10i2.662

\begin{abstract}
Resumo. Este artigo tem por objetivo analisar como as tecnologias digitais, em especial os fóruns de discussão, podem contribuir ou dificultar o ensino e o aprendizado do português. Tem-se como pressuposto teórico os estudos de Pierre Lévy e Vani Moreira Kenski, a priori, tais quais Cibercultura, Educação e Tecnologias, Tecnologias e Ensino Presencial e a Distância. As categorias de estudo são as tecnologias digitais na educação, modalidade EAD, Linguística Aplicada (LA) e Língua Portuguesa (LP). A pesquisa tem caráter qualitativo referenciada por pesquisas teóricas, em que se utilizarão de observações científicas, sempre contextualizando os referenciais e aplicando as teorias norteadoras da pesquisa. A relevância deste estudo dá-se para discutir ensino e aprendizagem do português por meio da observação de ambientes virtuais de aprendizagem, procurando discutir métodos e processos de desenvolvimento linguístico.
\end{abstract}

Palavras-chaves: Educação. Educação a distância. Tecnologias Digitais. LA. LP.

\begin{abstract}
This article aims to analyze how the digital technologies, especially the discussion forums, can help or hinder the teaching and learning of Portuguese. It has been assumed as theoretical bases the studies of Pierre Lévy and Vani Moreira Kenski, at first, such as Cyberculture, and Technology Education, Technology and Distance Education and Presential Teaching. The categories of study are digital technologies in education, distance learning, Applied Linguistics (AL) and Portuguese. The research is qualitative referenced by theoretical research, which will be used for scientific observations, always contextualizing benchmarks and applying the theories guiding the research. The relevance of this study is the discussing teaching and learning of Portuguese by means of the observation of virtual learning environments, seeking to examine methods and processes of language development.
\end{abstract}

Keywords: Education. Distance learning. Digital Technologies. AL. Portuguese.

\section{INTRODUÇÃO}

As discussões sobre ensino e aprendizagem da língua portuguesa são cada vez mais atuais tanto em relação à modalidade presencial quanto à não presencial. Assim, ao considerar o progresso da disponibilização da internet, o crescente número de pessoas com acesso à grande rede e o consequentemente aumento da demanda e da oferta de cursos por meio do sistema de Ensino a Distância, esta pesquisa buscou investigar de que forma as tecnologias digitais podem contribuir com esse processo pedagógico.

Antes, porém, os apontamentos de Lévy (1999) nos fazem refletir acerca da virtualidade e nos remete à realidade presente, quando o ensino a distância desponta para a sua democratização, uma vez que distâncias ge- ográficas podem ser superadas com o acesso a ambientes virtuais de aprendizagem por meio de uma conexão ativa com a internet. Por isso, a metodologia utilizada em ambientes virtuais tem similaridade com aaplicada em espaços presenciais.

Assim, pesquisas demonstram que o relevante diferencial na educação em geral é justamente o processo pelo qual se constrói o conhecimento, colaborativa e cooperativamente, tanto no ensino presencial quanto no a distância. Sob essa perspectiva, foi escolhido o meio da EAD por acreditar-se na democratização, portabilidade e acessibilidade das informações a serem discutidas e reelaboradas no processo de ensino e aprendizagem. É preciso que se prime pela disseminação com qualidade do ensino, em particular o do português. 


\begin{abstract}
Logo, as tecnologias modernas podem ser aliadas no processo de ensino e aprendizagem do português, apesar dos preconceitos a que o próprio falante, muitas vezes, submete a língua. Indispensável essa consciência de identidade linguística e cultural e das suas necessidades sociais nas esferas de comunicação. Nesse sentido, as tecnologias modernas podem apresentar novas alternativas para esse processo.

A Linguística Aplicada (LA), em comunhão com as novas tecnologias, tem desenvolvido processos de compreensão e assimilação da língua. Isso contribui sobremaneira para pensar e fazer o ensino do português de forma mais consciente e objetiva, em circunstância de transposição de fronteiras geográficas, ao convocar os sujeitos do processo para a construção do conhecimento por meio da interação e da colaboração.
\end{abstract}

De base qualitativa, esta pesquisa caracteriza-se como bibliográfica. A tipologia empregada pressupõe identificação do material, seleção e análise para iniciarse o estudo a que se propõe.Sendo assim, esta pesquisa necessitou da escolha criteriosa de livros, periódicos e trabalhos acadêmicos.

Destarte, no decorrer da pesquisa serão discutidos elementos essenciais à boa prática do ensino e aprendizagem do português com atenção ao uso das novas tecnologias digitais, tudo fundamento na LA. Daí a importância da leitura de Lévy (1999) e suas pesquisas acerca da tecnologia e cultura no mundo virtual, ao lado do exame das práticas e estudos de Kenski (2003), Kenski (2007) etc., a fim de se buscar o elo entre a tecnologia e o ensino do português.

\section{A IMPORTÂNCIA DA LINGUÍSTICA APLI- CADA AO ENSINO DO PORTUGUÊS}

Antes de tudo é preciso discutir a importância da educação linguística para a sociedade. A necessidade de educar o sujeito/ator da língua surge para quea comunidade possa construir a si mesma e ao próprio indivíduoenquanto nativo da língua, consoante se vê nas palavras de Bagno e Rangel (2005):

Entendemos por educação linguística o conjunto de fatores socioculturais que, durante toda a existência do indivíduo, lhe possibilitam adquirir, desenvolver e ampliar o conhecimento de/sobre sua língua materna, de/sobre suas línguas, sobre a linguagem de um modo mais geral e sobre todos os demais sistemas semióticos. Desses saberes, evidentemente, também fazem parte as crenças, superstições, representações, mitos e preconceitos que circulam na sociedade em torno da língua/linguagem e que compõem o que se poderia chamar de imaginário linguístico ou, sob outra ótica, de ideologia linguística. Inclui-se também na educação linguística o aprendizado das normas de comportamento linguístico que regem a vida dos diversos grupos sociais, cada vez mais amplos e varia- dos, em que o indivíduo vai ser chamado a se inserir. (BAGNO E RANGEL, 2005, p. 1)

Para os referidos autores, as práticas ainda estão distantes da realidade brasileira, o que deixa a desejar quanto a essa educação linguística em especial. Isso requer mais engajamento da academia com a sociedade e o consequente despertar dos atores sociais e usuários da língua para essa construção científica da língua.

Nessa mesma linha de análise, devido a essa distância entre a academia e a sociedade na educação linguística, a formação docente básica não contempla essa discussão, senão pelos cursos de Letras, os quais também ainda deixam a desejar quanto à prática educativa da língua. E se não há essa aproximação, muitos são os prejuízos para os atores da língua, ainda pouco conscientes do seu papel nessa construção social, o que gera preconceitos linguísticos, sociais e culturais.

Aumenta-se, consequentemente, a condição de poder entre as classes sociais, quando se detém a norma culta nacional, bem como uma realidade regional em deturpação de outra. Exemplo clássico é a mídia televisiva que impõe o discurso e a linguagem sudestes para toda a nação. Isso se reflete, inclusive, no modo de pensar, agir, vestir, falar, economizar etc.Também nas leituras e produções acadêmicas de toda a nação e, ainda mais, na educação básica, quando o sujeito está em formação, a estrutura educacional não contempla a formação do profissional docente; este, por vezes, é o que primeiro comete preconceitos de toda ordem, em especial o linguístico.

Dessa forma, uma das ações propostas por Bagno e Rangel (2005, p. 68) "é a pedagogia da educação em língua materna praticada na escola”, dentre outros apontamentos, inclusive com a "produção de uma gramática de referência do português brasileiro, não normativa e suficientemente acessível ao leitor comum" (Idem, p. 71). Isso, pois, depende de discussões específicas da comunidade acadêmica com abertura social, a fim de que, mudando-se o pensamento dos atores, modifique-se a estrutura normativa para a construção linguística sólida com eficiência e eficácia. Destaca-se, enfim, a tarefa da educação linguística: conscientizar os atores da língua quanto aos paradigmas e às possibilidades de reinvenção linguística, o que de fato ocorre constantemente.

Nessa mesma visão, a escola deve ensinar a norma culta paralelamente ao ensino de regras alternativas, deixar claro o que é a língua, a sua estrutura e o seu funcionamento, a fim de promover um ensino linguístico de qualidade. Assim, o indivíduo se tornará consciente do seu papel atuante na língua como ser social e serão reduzidos os preconceitos, tanto na língua quanto 
na vida cotidiana.

A partir desse ponto de vista, apresenta-se a LA, enquanto ciência interdisciplinar, ciência moderna e independente da Linguística, que procura atender a um público específico, de forma objetiva, coerente e coesa, baseada em métodos práticos, inclusive com o uso de tecnologias para averiguações, explanações e "correções" de problemas demandados pelo usuário da língua.

Nesse meio, há de se reconhecer que o processo comunicacional está em constante mudança. As línguas mudam no decorrer do tempo, umas morrem e dão lugar a outras, mas sempre há interseção, ainda que em menor grau, entre língua dominada e predominante. Também há a crescente melhoria da qualidade das conexões de internet, inclusive no Brasil, o que propicia melhor comunicação por vídeo e voz. Isso pode acarretar em mudanças nas posturas dos interlocutores, os quais poderão se preocupar com suas posturas corporais, gestos e até com suas falas.

Sendo assim, a LA parte da interação entre as ciências para buscar uma solução social, não apenas fixando o estudo de determinado objeto, por curiosidade, mas procurando contribuir com os anseios e demandas sociais concernentes à linguagem, segundo Leffa (2001). E nessa interseção, as tecnologias digitais podem contribuir sobremaneira com ensino e aprendizagem da língua, uma vez que elas rompem barreiras impostas ao sistema de ensino tradicional presencial.A LA acrescenta, então, ao ensino do português à medida que considera também esse contexto atual de uso das tecnologias, atendendo a uma construção social do conhecimento:

$$
\begin{aligned}
& \text { [...] a Linguística Aplicada pretende contribuir para que } \\
& \text { haja o entendimento de que a linguagem humana é so- } \\
& \text { cialmente construída, o que acarreta desenvolver no pro- } \\
& \text { fessor uma conscientização política com relação aos pro- } \\
& \text { blemas inerentes à linguagem e sua vinculação com o } \\
& \text { contexto social. (SOARES, 2010, p. 15) }
\end{aligned}
$$

Portanto, a LA, ao levar em conta as demandas sociais, reconhece que o uso das tecnologias tem papel importante na aprendizagem em geral, pois, por meio das ferramentas interativas digitais, também se (re)constrói o saber, como bem explica Kenski (2003):

\footnotetext{
Interagir com as informações e com as pessoas para aprender é fundamental. Os dados encontrados livremente na internet transformam em informações pela ótica, pelo interesse e pela necessidade com que o usuário os acessa e os considera. Para a transformação das informações em conhecimentos é preciso um trabalho processual de interação, reflexão, discussão, crítica e ponderações que é mais facilmente conduzido quando partilhado com outras pessoas. As trocas entre colegas, os múltiplos posicionamentos diante das informações disponíveis, os debates e as análises críticas auxiliam a
}

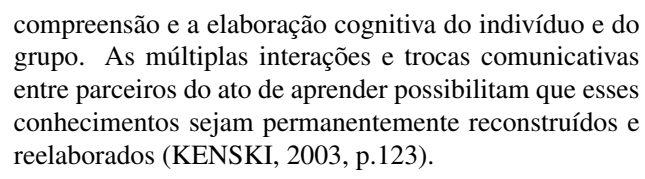

compreensão e a elaboração cognitiva do indivíduo e do grupo. As múltiplas interações e trocas comunicativas entre parceiros do ato de aprender possibilitam que esses conhecimentos sejam permanentemente reconstruídos e reelaborados (KENSKI, 2003, p.123).

Enfim, é importante compreender que o uso das tecnologias para o ensino muda todo o processo de aprendizagem. Exemplos são os grupos de estudantes e professores que interagem por meio de redes sociais e de mensageiros digitais, no intuito de comunicação rápida e de mais informações.

\section{AS FERRAMENTAS NOS AMBIENTES VIR- TUAIS DE APRENDIZAGEM QUE PODEM CONTRIBUIR PARA A COMPREENSÃO E DISCUSSÃO DA LÍNGUA MATERNA}

Em vista do crescimento interacional entre os usuários da língua, além de sua inserção no contexto das tecnologias, faz-se necessário identificar as ferramentas que contribuem para a melhoria da comunicação e do aprendizado do português nos cursos online.

$\mathrm{O}$ ambiente virtual de aprendizagem é referência à própria estrutura da instituição de ensino, onde se devem encontrar as salas de aula, o pátio para conversas aleatórias, a biblioteca, a administração, a coordenação, a tesouraria etc. Particularmente à questão pedagógica, são fundamentais as ferramentas tecnológicas no ensino a distância. Estas podem ser classificadas em síncronas e assíncronas (quanto à temporalidade), sendo as primeiras: chats, web conferências, teleconferências; e as últimas: textite-mails, fóruns, vídeos, material impresso, e-books etc.

No tocante às pesquisas na internet, isso pode ser frutífero tanto para o professor quanto para o aluno, uma vez que, a cada dia, mais informações estão dispostas na rede mundial de computadores. Porém, a gama de informações também é um problema. Como encontrar os elementos que melhor se ajustam ao que se pede? Que ferramentas podem ajudar nesse processo? Segundo Moran (2007), awebquest pode contribuir para o desenvolvimento de pesquisas em grupo, quando se observa o valor colaborativo dos estudos na internet:
Uma das formas mais interessantes de desenvolver pesquisa na internet é a webquest. Trata-se de uma atividade de aprendizagem que aproveita a imensa riqueza de informações que, dia a dia, cresce na Internet. Resolver uma webquest é um processo de aprendizagem atraente porque envolve pesquisa, leitura, interação, colaboração e criação de um novo produto a partir do material e ideias obtidas. A webquest propicia a socialização da informação: por estar disponível na internet, pode ser utilizada, compartilhada e até reelaborada por alunos e professores de diferentes partes do mundo. O problema 


\begin{abstract}
da pesquisa não está na internet, mas na maior importância que a escola dá ao conteúdo programático do que à pesquisa como eixo fundamental da aprendizagem (MORAN 2007).
\end{abstract}

Nesse caso, um dos maiores empecilhos para o aprendizado pode ser justamente a escola com seus rígidos padrões. Aliado a isso, ainda se tem pouco dos estudos linguísticos como base formativa do cidadão. Frente a tais problemas, é preciso reconhecer a necessidade do uso das ferramentas colaborativas na internet, a fim de chamar o sujeito para a pesquisa e a descoberta desse mundo da língua.

Diante dessa carência, o uso dos fóruns e das comunidades de discussão, ferramentas assíncronas, pode intermediar esse processo de ensino e aprendizagem, muito embora todas as ferramentas sejam importantes para a construção do aprendizado. Dando maior condição de ruptura do tempo, ou seja, o aluno tem maior liberdade de postar seu pensamento a qualquer hora, a ferramenta fórum propicia discussões de boa qualidade. Nesse contexto, "[...] a interação entre as pessoas podem (sic) ser eventuais, isoladas e interrompidas, mas podem ao contrário, possibilitar relações colaborativas ou cooperativas que ultrapassem o ato de interagir por interagir" (VENTURA, 2011, p. 215).

Assim é que se dá a importância da interação para a construção do saber, ainda mais quando se trata de ensino e aprendizagem da língua, o que se pode ver por intermédio da metalinguagem, em textos que envolvam a curiosidade e o interesse do aluno.

No espaço do fórum de discussão, o aluno pode verificar os comentários e o aprofundamento das discussões. Desse modo, logo após realizar a leitura do material de estudo, o educando pode elaborar sua participação em um editor de texto, momento em que deve rever e editar essa postagem de forma que atenda à(s) proposição(ões), bem como às regras normativas e de estilo cabíveis para, em seguida, copiar e colar no espaço próprio do fórum. Essa medida também serve de segurança caso haja problemas de conexão com a internet ou com o site. Portanto, o editor de texto é uma ótima ferramenta para se trabalhar nos fóruns de discussão, pois permite a revisão ortogramatical, semântica etc.

Dentre as ferramentas assíncronas, os fóruns de discussão apresentam maior liberdade de interação emaior tempo de elaboração do enunciado. Dessa forma, eles podem ser caracterizados como uma atividade pedagógica plena, ainda mais para o estudo da língua, visto que esses ambientes virtuais proporcionam: a sua utilização direta; a elaboração do pensamento; a concretização da língua; a revisão; e a interação como fatores primordiais para o aprendizado. Nesse aspecto, David et al. (2006) apresentam:

Vygotsky (2003) considera que o processo de interação entre os indivíduos desempenha um papel fundamental na construção do ser humano, pois é nas relações interpessoais que o indivíduo internaliza as formas culturalmente estabelecidas de funcionamento psicológico. Portanto, a interação social, seja diretamente com outros membros da cultura, seja através de diversos elementos do ambiente culturalmente estruturados, fornece a matéria prima para o desenvolvimento psicológico do indivíduo, na medida em que possibilita o compartilhamento de sistemas simbólicos, a internalização de tais sistemas e o desenvolvimento propriamente dito (DAVID et al., 2006, p.208).

Nesse sentido, o Construcionismo é essencial para o desenvolvimento do indivíduo e, em especial, da sua linguagem e da sua compreensão do mundo. Os fóruns podem ser capazes de demonstrar essa riqueza, inclusive, quando apresentam traços da oralidade, o que remete a outros estudos específicos. Contudo, cabe ao mediador desse processo, o tutor, mostrar os níveis da linguagem e o seu emprego adequado para cada situação social, aplicando, pois, os preceitos linguísticos.

Quanto aos chats, eles são importantes, dentro das ferramentas síncronas, por aproximarem seus operadores. Porém, como não se sabe, geralmente, quem está escrevendo algo, muitas postagens ocorrem simultaneamente, sobrecarregando de informações o ambiente. Comparando a uma sala de aula presencial, é como se todos falassem a um só tempo, o que também pode dificultar a atenção do tutor ao conduzir os trabalhos e, no mínimo, pode baixar a qualidade do atendimento ao aluno participante, segundo se observou em participaçõesde cursos e congressos feitas pela internet.

Contudo, todo o conjunto dependerá de outros fatores como a habilidade do tutor em conduzir o assunto e os questionamentos, bem como o potencial e a dedicação dos aprendizes no cumprimento das atividades. Além disso,o número de participantes no chat tem significativa influência na qualidade de ensino e aprendizagem, pois, igualmente à sala de aula presencial, o professor melhor orienta com um número reduzido de participantes.

Importante destacar o uso das tecnologias para o proveito coletivo e a facilitação da compreensão geral, conforme expõe Leffa (2001):

\footnotetext{
[...] não basta pôr o aluno em contato direto com um exemplo de uso da língua; é preciso tornar a língua compreensível para o aluno. Isso é feito basicamente pela mediação de materiais de ensino, incluindo explicações, sugestão de estratégias, fornecimento de pistas, etc. (LEFFA, 2001, p.13).
}

E, a partir disso, é possível pensar novas formas de realização do ensino e do aprendizado, contando também com as tecnologias do momento, oportunidade em 
que é necessário saber em qual medida isso contribui ou não com o processo de ensino e aprendizagem. A par dessa ideia, é necessário discutir numa proposta de pesquisa estrita, analisando-se finalmente os estudos da língua portuguesa dentro desse processo comunicacional, neste caso tendo como material de estudo as propostas e ementas das disciplinas que envolvem a língua portuguesa.

De antemão, a literatura específica aponta para que o projeto pedagógico seja a base e o princípio norteador do ensino. Portanto, de tal documento dependeria o sucesso do processo de ensino e aprendizagem. Ainda mais quando se trata de educação online, a qual necessita de uma equipe multidisciplinar para a construção e implementação do projeto, consoante dispõe o documento de Referenciais de qualidade para educação superior a distância (BRASIL, 2007).

\section{ASPECTOS QUE FACILITAM E DIFICULTAM O ENSINO A DISTÂNCIA DO PORTUGUÊS}

Considerando a crescente necessidade de se formar o cidadão consciente e ativo quanto a sua própria língua, bem como a crescente acessibilidade aos meios digitais de comunicação, a relevância deste estudo consiste em discutir o ensino da língua portuguesa no Brasil com foco no aproveitamento dos ambientes virtuais de aprendizagem. A ideia, então, é "romper barreiras", oportunizar a recriação de métodos e o desenvolvimento linguístico, a fim de fomentar reflexões acerca da língua e dos métodos pelos quais se ensina e se aprende o idioma. Dessa forma, a inclusão digital deve ser crescente para formar e informar melhor o cidadão enquanto usuário do português, portador de direitos e deveres, dependente da língua para expressar-se socialmente.

Nessa direção, um dos aspectos facilitadores apontados por esta pesquisa é precisamente o processo de interação para a construção do saber. De maneira oposta, a falta de interação pode dificultar sobremaneira o aprendizado, consoante aponta Kenski (idem):

É (...) participando, colaborando, reconhecendo e sendo reconhecida pelos seus pares, que a pessoa que atua intensamente na comunidade virtual sente seu poder, desenvolve suas potencialidades comunicacionais, libera seus talentos. Mais ainda, socialmente integrada na equipe, a pessoa dimensiona sua participação de acordo com os valores e regras em jogo, realiza trocas e aprende muito mais do que o foco específico de seu interesse (KENSKI, 2003, p.129).

Entretanto, num primeiro momento, é necessária a observação de alguns pontos, como: a acessibilidade aos usos das tecnologias digitais; a qualidade do ambiente virtual de aprendizagem; o material didático desenvolvido exclusivamente para esse fim por equipe multidisciplinar; o treinamento e a capacitação dos atores envolvidos nesse processo. Todo esse procedimento básico deve ser precedido de estudo específico e dirigido por profissionais da área da educação, tecnologias da informação e comunicação, LA e português. Cabe, pois, o ensinamento de Santos (2011):

\begin{abstract}
Acreditamos que o revigoramento da qualidade da educação está intimamente associado aos processos de ensino e aprendizagem. Nesta direção, focamos a realidade vivenciada em sala de aula, no tocante ao estabelecimento de articulações entre teoria e prática, repensandose os caminhos da prática pedagógica e o desenvolvimento cooperativo do processo de aprendizagem significativa e de construção de novos conhecimentos (SANTOS, 2011, p.254).
\end{abstract}

Trazendo esse pensamento para a prática pedagógica do português, vê-se que é possível considerá-lo, no ensino semipresencial e a distância da língua, na formação da prática docente. Essa necessidade do revigoramento da qualidade educacional aplica-se perfeitamente ao português, especialmente quando se pensa na aplicação pedagógica das tecnologias digitais e na reflexão sobre métodos antigos e modernos no ensino da língua.

Outra consideração a propósito do assunto é a forma da prática pedagógica do português, quando o estudo da língua, por ser socialmente construída, requer o estudo social e cooperativo dos seus interagentes. Em tais circunstâncias, torna-se necessário, pois, estudar essas práticas dentro de articulações e pensamentos da própria comunidade acadêmica. De forma geral, assim contribui o pensamento de Prata (2008):

\footnotetext{
O fazer docente profissional não é algo que acontece de forma isolada, apenas na formação em nível de graduação, absorvendo teorias e mais teorias, sem fazer uma relação com a prática, é todo um conjunto. O professor não é o único responsável pela sua formação, ele sofre interferências, como formação escolar, formação acadêmica, do processo educativo em geral e da sociedade como um todo (PRATA, 2008, p.313)
}

Talvez, um dos maiores desafios para o aprendizado em ambientes virtuais seja fazer com que o aluno interaja de forma eficiente, eficaz e colaborativa. Neste caso de colaboração, diferentemente de cooperação (divisão de trabalho), é necessário realizar conexões das ideias de todos os participantes, levando para o ambiente contribuições de outros autores estudados.

Por outro lado, manter a atenção do aluno e estimulá-lo a participar requerem boa habilidade técnica e afetiva do tutor, o qual não deve somente mediar a construção do saber no ambiente, mas chamar o 
aluno à construção, se necessário até individualmente, ponderar as postagens, elogiar sua participação etc.

Além do aspecto de que a escola e o professor não têm, geralmente, a intimidade devida com o aparato tecnológico, tanto quanto o aluno, ainda há outras questões que dificultam o processo pedagógico com o uso das tecnologias digitais.

Para Soares (2010), há distração contínua ao se navegar pela internet, realizando leituras de $e$-mails, conversas online, leitura e participação em redes sociais etc., além do que não se lê somente o que se apresenta, mas há vários hiperlinks conectando o leitor a vários outros assuntos. Nisso, abstrai-se o pensamento e a leitura pode tornar-se superficial, se comparada à leitura convencional de um livro impresso.

Em segundo ponto, a escrita virtual, substituindo o papel e abreviando palavras e expressões, cria um código próprio ao se navegar pela internet. Isso reflete tanto a pressa para se comunicar teclando, quanto também a pouca prática dos usos do português formal. Isso em particular deve ser visto com reservas, sem preconceitos linguísticos, mas procurando deixar essa linguagem para um bate-papo informal, por exemplo, e não para o contexto de escritas formais de trabalhos acadêmicos e escolares, documentos etc.

Como terceiro ponto negativo, o referido autor cita a linguagem na internet ou a Comunicação Mediada por Computador (CMC), não se confundindo com a escrita virtual, quando a CMC envolve muito mais fatores, porquanto não só a linguagem escrita, mas toda a diversidade envolvente de imagens, sons e palavras.

Destarte, as marcas da oralidade levadas para a escrita no ambiente virtual podem ser vistas como ponto positivo, uma vez que as ferramentas assíncronas, por demandarem maior tempo de postagem, servem justamente como meio de apreensão da língua. É possível realizar exercícios de escrita ao passo que se desenvolve o pensamento lógico. Também a partir da gramática normativa, os interagentes podem aplicar várias maneiras de reconhecer a linguagem empregada, inclusive a partir de textos literários, quando se pode trabalhar a linguagem por época de escrita, observar as mudanças no decorrer do tempo, enfim, a evolução e o emprego da língua, a depender de qual objetivo se queira atingir em relação ao interlocutor.

Cabe, pois, primeiramente, a estruturação profícua do projeto pedagógico voltado para o uso das tecnologias digitais, bem como a sua viabilização. Assim, com o apoio dessas tecnologias cada vez mais presentes no cotidiano, pode-se conduzir o aprendente a descobrir a melhor maneira de pesquisar e aprender, o que de fato dá-se interagindo com outros sujeitos, outros pensamentos, outras culturas e até outras linguagens, considerando-se a variedade linguística brasileira. O sujeito consciente da língua constrói a si mesmo e, assim,erige o outro nesse processo interacional infinito, o que resulta em aprendizado coletivo.

Afinal, há vários fatores que contribuem ou não com o aprendizado do português por meio da internet, o que faz dessa temática merecedora de uma pesquisa mais abrangente. Entretanto, o projeto pedagógico é fundamental para que algumas arestas sejam previstas antes da sua execução, na construção do Ambiente Virtual de Aprendizagem, na elaboração do material de estudo, na capacitação do tutor, dentre outros aspectos.

É possível, mediante as tecnologias, conduzir o aluno para o que interessa no curso, orientando-o, estimulando-o a participar e interagir por intermédio das leituras e do que o ambiente virtual disponibiliza. Quando há engajamento, o compromisso individual torna-se coletivo e, à medida que os alunos descobrem e conhecem, outros saberes são requisitados. Assim, os agentes da aprendizagem utilizarãoainda mais suas experiências para a construção desse processo. É importante, pois, que as vivências de cada um sejam compartilhadas e discutidas dentro de um ambiente propício ao exercício da construção coletiva do saber.

\section{CONSIDERAÇÕES FINAIS}

Não existe aqui a intenção de encerrar o assunto. Pelo contrário, a ideia é suscitar algumas questões para fortalecer a temática nos educadores. Desse modo, é imprescindívela atenção aos fóruns, em cujas participações os alunos têm o dever de escrever e de aprimorar suas escritas, pensamentos e ideias. Por isso, somos favoráveis aos cursos na modalidade a distância onde haja interações.

Sendo assim, no ensino do português, as tecnologias devem somar e o tutor precisa apropriar-se delas para chamar os alunos a pensar a língua, escrevendo, discutindo, aplicando os preceitos linguísticos sem o rigor da gramática normativa, mas nunca a esquecendo. Ou seja, é preciso ter ciência gramatical, mas não se engessar com ela, o que depende muito da sensibilidade do tutor e, bem antes, do projeto pedagógico.

Por essa razão, o uso das tecnologias precisa ser estimulado, pois é um fato e está cada vez mais em crescimento, tanto por razões de aumento de acesso à internet, quanto também da crescente capacidade da rede. Logo, estudar a língua portuguesa por meio das tecnologias digitais é expandir as possibilidades de conhecê-la melhor.

Se as redes sociais e mensageiros digitais propiciam a escrita de qualquer forma, também permitem a escrita 
AS TECNOLOGIAS DIGITAIS NO ENSINO E NA APRENDIZAGEM DO PORTUGUÊS.

que seja comunicável e criativa, sem a apropriação do absurdo, da criação de um novo código. É nesse aspecto que a LA deve ser observada pelo sistema educativo: permitir a comunicação e ressaltar a estrutura da língua por meio da comunicação digital. Os meios são muitos, como o whatsapp.com, facebook.com, passeidireto.com, dentre outros. O que faz a diferença é modo de conduzir a aprendizagem e os interesses dos envolvidos.

A bem da verdade, os alunos no ensino presencial têm deveres de casa e atividades extracurriculares. De posse de equipamentos digitais e da internet, eles trocam informações e pesquisas, enviammateriais de estudo, trabalhos etc. Resta aos educadores entrar nesse mundo digital e acompanhar o andamento da aprendizagem. Dessa forma, comunicando-se, os atores do processo devem ter em mente o uso das ferramentas digitais para amoldar o aprendizado da língua portuguesa. O uso das ferramentas digitais para a prática da língua pode fazer uma enorme diferença na hora de escrever um texto formal, como uma redação, um artigo etc.

Importante, pois, pensar o uso das tecnologias digitais mais recentes em busca de melhorar a educação, tanto porque as tecnologias são uma realidade em plena expansão, quanto porque é necessário melhorar os processos de ensino e aprendizagem. Por isso Lévy (1999) discursa acerca da nova realidade, a virtual, a qual não é algo abstrato, mas real, porque faz parte da sociedade moderna. A virtualidade é utilizada pelos usuários de forma a torná-la real, porque presente e significativa, usando-se os vários sentidos requeridos como a emoção, a razão, o feedback etc.

Enfim, as aulas de português devem fazer referência aos livros e à leitura, seja de forma impressa ou digital. A partir da leitura, a construção textual no mundo virtual pode ser envolvente e é umaforma de chamar o aprendente a participar, tornando realidade todas as ações disponíveis no ambiente virtual.

\section{REFERÊNCIAS}

BAGNO, M.; RANGEL, E. d. O. Tarefas da educação linguística no Brasil. Revista Brasileira de Linguística Aplicada, v. 5, n. 1, 2005. Disponível em: <http://www.scielo.br/pdf/rbla/v5n1/04.pdf> Acesso em: 06 fev. 2013.

BRASIL. Secretaria de Educação a Distância. Ministério da Educação e Cultura. Referenciais de qualidade para a educação superior a distância. 2007. Disponível em: <http://portal.mec.gov.br/seed/ arquivos/pdf/legislacao/refead1.pdf>. Acesso em: 19 jul. 2015
DAVID, P. B.; FILHO, J. A. C.; SPINILLO, A. G.; SIQUEIRA, R. A. Gêneros assíncronos: instrumentos de interação em ambientes virtuais de aprendizagem. In: XXVI CONGRESSO DA SOCIEDADE BRASILEIRA DE COMPUTAÇÃO. Campo Grande: Anais do Congresso Sbc, 2006. p. 9. Disponível em: <http://www.br-ie.org/pub/index.php/ wie/article/view/893/879> Acesso em: 07 mar. 2013.

KENSKI, V. M. Tecnologias e ensino presencial e a distância. 9. ed. Campinas: Papirus, 2003.

Educação e Tecnologias: o novo ritmo da informação. 6. ed. Campinas: Papiros, 2007.

LEFFA, V. J. A linguística aplicada e seu compromisso com a sociedade. In: VI CONGRESSO BRASILEIRO DE LINGUíSTICA APLICADA, 6. 2001, BELO HORIZONTE. Anais do VI Congresso Brasileiro de Linguística Aplicada. Belo Horizonte: Ufmg, 2001. p. $1-15$.

LÉVY, P. Cibercultura. 3. ed. São Paulo: 34, 1999.

MARTINS, C. A.; VASCONCELOS, F. H. L.; OLIVEIRA, F. K.; SANTANA, J. R.; SOUSA, M. I. P. de. In: SANTANA, J. R.; VASCONCELOS, J. G.; CECATTO, V. M. (Ed.). Inovações, Cibercultura e Educação. Fortaleza: Edições UFC, 2011. 309 p.

MORAN, J. M. As possibilidades das redes de aprendizagem. In: MORAN, José Manuel. A educação que desejamos: novos desafios e como chegar lá. 2. ed. Campinas: Papirus, 2007. p. 89 - 111. Disponível em: <http://www.eca.usp.br/prof/moran/site/textos/> Acesso em: 16 jul. 2015.

PRATA, G. C. F. B. FORMAÇÃO DOCENTE: (RE) CONSTRUINDO-SE PROFESSOR REFLEXIVO. In: MORAES, Silvia Elizabeth (Org.). Currículo e formação docente: um diálogo interdisciplinar. Campinas: Mercado das Letras, 2008. p. 307-316.

SANTOS, M. J. C. Olhares na educação científica e matemática: holístico, interdisciplinar, aprendizagem significativa e m-learning. In: SANTANA, José Rogério et al (Org.). Inovações, Cibercultura e Educação. Fortaleza: Edições Ufc, 2011. p. 253-282.

SOARES, D. d. A. A linguística aplicada no brasil. In: FACULDADE INTEGRADA DA GRANDE FORTALEZA (Brasília) (Org.). Introdução à

Linguística Aplicada. Brasília: Fgf, 2010. p. 23. Livro destinado ao curso de pós-graduação em Tecnologias e Educação a Distância. 
VENTURA, P. P. B. Interações sociais em comunidades virtuais de aprendizagem. In: SANTANA, José Rogério et al (Org.). Inovações, Cibercultura e Educação.

Fortaleza: Edições Ufc, 2011. p. 213-235.

\section{AGRADECIMENTOS}

À Revista Conexões, seus editores, professores e funcionários: é uma honra interagir e aprender com todos! 